\title{
INFLUENCE OF THE LONG TERM USE OF A COMPUTER ON MEDIAN, ULNAR AND RADIAL SENSORY NERVES IN THE WRIST REGION
}

\author{
BELGIN BAMAC ${ }^{1}$, SERAP COLAK ${ }^{2}$, GULMINE DUNDAR ${ }^{3}$, HAMIT MACIT SELEKLER ${ }^{3}$, YAVUZ TAŞKIRAN ${ }^{2}$, \\ TUNCAY COLAK ${ }^{1}$, and EMIN BALCI ${ }^{1}$
}

${ }^{1}$ Kocaeli University, Kocaeli, Turkey

Faculty of Medicine, Department of Anatomy

${ }^{2}$ Kocaeli University, Kocaeli, Turkey

School of Physical Education and Sports

${ }^{3}$ Kocaeli University, Kocaeli, Turkey

Faculty of Medicine, Department of Neurology

\begin{abstract}
Objectives: Repetitive microtrauma or overuse injuries may often affect upper extremities of the long term computer users. The aim of this study was to compare sensory nerve conduction velocities (SNCV) for median, radial and ulnar nerves in the wrist of computer users with the same parameters in controls who do not use computers regularly. Material and Methods: Twenty one male computer users (age: mean $(M)=28.3$ years \pm standard deviation $(S D)=7.5$ years) and 21 male control subjects (age: $\mathrm{M} \pm \mathrm{SD}=24.1 \pm 4.6$ years) were recruited for the study. Limb length and the perimeters of the dominant arm and forearm were measured for each subject. The neurophysiological study consisted of measuring sensory nerve conduction of the median, ulnar and radial nerves. Results: The sensory conduction velocities of both median and ulnar nerves were significantly delayed in the dominant arm of the computer users compared to the controls. In addition, sensory conduction velocity of the median nerve was significantly delayed in the dominant extremity of the computer users compared to their non-dominant extremity. Conclusions: This study shows that computer users have a tendency toward developing median and ulnar sensory nerve damage in the wrist region. Mechanism of delayed SNCV in the median and ulnar nerves may be due to sustained extension and ulnar deviation of the wrist during computer mouse use and typing. Reduced SNCV changes were more apparent on the dominant side of the median nerve. This may indicate the increased neural deficits related to an increased use of the dominant side. Further investigation is needed to determine how to reduce potential risk factors at this stage in order to prevent development of median or ulnar neuropathy in the long term computer users.
\end{abstract}

Key words:

Computer users, Ulnar, Median, Radial, Nerve

\section{INTRODUCTION}

Intensive computer work can increase the risk of developing neuromusculoskeletal symptoms and disorders in the upper extremities. There is a general consensus in the literature that computer use is often associated with an increased prevalence of hand and wrist disorders [1-4]. Associations between computer use and neuromusculoskeletal disorders of the wrist have been related to repetitive motions, non-neutral postures and consistent static muscle loading. Symptoms may be associated with specific

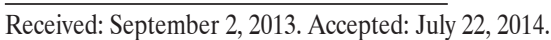

Corresponding author: B. Bamac, Kocaeli University, School of Medicine, Department of Anatomy, Umuttepe, 41380, Kocaeli, Turkey (e-mail: bbamac@hotmail.com). 
clinical entities such as peripheral nerve entrapment. Certain postures or positions can place increased pressure either directly or by increasing tension on the nerves at different entrapment points [5].

In this study, sensorial nerve conduction velocities were evaluated, because it has been stated that nerve sensibility is affected in the early stage of nerve entrapment, while an impaired motor function occurs at a latter stage of the neuropathy [6]. We have proposed that computer users have developed minor neural injury as a consequence of restricted gliding or compression of the median, ulnar or radial nerves. Therefore, this study was performed to evaluate the effect of long term use of a computer on the median, ulnar and radial nerves crossing the wrist region among computer users with musculoskeleal symptoms.

\section{MATERIAL AND METHODS}

\section{Participants}

Twenty one male computer users (age: mean $(\mathrm{M}) \pm$ standard deviation $(\mathrm{SD})=28.33 \pm 7.51$ years) and 21 male control subjects (age: $\mathrm{M} \pm \mathrm{SD}=24.19 \pm 4.60$ years) volunteered to participate in the study. Table 1 shows physical characteristics of the subjects. All of the subjects were informed about the study procedures, purposes, benefits and known risks and gave their informed consent. The subjects were able to withdraw from the study at any time. The inclusion criteria for the group of computer users were: - having practiced on a conventional computer keyboard and mouse for a minimum of $4 \mathrm{~h}$ per day as part of regular work for at least 5 years,

- no history of surgery or any traumatic upper extremity lesions including past or current neurological impairment.

The group of computer users included the following occupations: administrators, personal computer support, librarians and medical secretaries. The control group consisted of university staff and students with less than $2 \mathrm{~h} /$ day of computer use (keyboard or mouse). They had no history of surgery or any traumatic upper extremity lesions including past or current occurrences of neurological impairment and no musculoskeletal complaints. We excluded participants with metabolic diseases, such as diabetes, that may be associated with entrapment neuropathy. A participant with numbness, burning or tingling in the hands/wrists or fingers was also excluded from the study. All the participants were right hand dominant.

Questionnaires regarding musculoskeletal symptoms were distributed among the computer users. The musculoskeletal

Table 1. Characteristic of the study groups including computer users and controls

\begin{tabular}{|c|c|c|c|}
\hline \multirow{2}{*}{ Parameter } & \multicolumn{2}{|c|}{$\begin{array}{l}\text { Study group } \\
(\mathrm{M} \pm \mathrm{SD})\end{array}$} & \multirow{2}{*}{$\mathrm{p}$} \\
\hline & $\begin{array}{l}\text { computer users } \\
(\mathrm{N}=21)\end{array}$ & $\begin{array}{l}\text { controls } \\
(\mathrm{N}=21)\end{array}$ & \\
\hline Age (years) & $28.33 \pm 7.51$ & $24.19 \pm 4.60$ & 0.040 \\
\hline Height (cm) & $180.95 \pm 6.53$ & $178.66 \pm 3.83$ & 0.216 \\
\hline Weight (kg) & $79.42 \pm 10.82$ & $73.14 \pm 4.71$ & 0.016 \\
\hline Perimeter of dominant forearm $(\mathrm{cm})$ & $25.58 \pm 2.16$ & $25.20 \pm 2.27$ & 0.778 \\
\hline Perimeter of arm $(\mathrm{cm})$ & $30.80 \pm 2.07$ & $30.88 \pm 2.04$ & 0.353 \\
\hline Length of upper extremity $(\mathrm{cm})$ & $77.80 \pm 4.04$ & $77.71 \pm 3.28$ & 0.768 \\
\hline
\end{tabular}

$\mathrm{M}$ - mean; SD - standard deviation. 
questionnaire inquired about ache, pain or discomfort during the previous 6 months from 5 specific regions of the upper body (neck, shoulder, elbow, wrist and hand). Fifteen subjects reported bilateral symptoms, and 6 reported unilateral dominant side symptoms.

\section{Neurophysiological tests}

The neurophysiological study consisted of measuring sensory nerve conduction velocity (SNCV) of the ulnar, median and radial nerves. The nature of the procedure was explained to the subjects. The subjects lay supine on a padded table with the upper limb supported. All of the studies were performed in a warm room with temperature of $26-28^{\circ} \mathrm{C}$. The skin temperature of the upper limb was monitored in order to eliminate the influence of temperature on the conduction parameters. If necessary, the limb was warmed under an infrared heat lamp to maintain a temperature of $32^{\circ} \mathrm{C}$ or higher. In an effort to reduce diurnal variation, in the case of each subject all of the measurements were taken at approximately the same time of day. The intercathodal distances were measured with an anthropometer. The dominant extremities of all the subjects were tested by a neurologist using a Neuropack M1, MEB-9204K (Nihon Kohden, Japan). The electrophysiological study was conducted according to the practice guidelines of the American Association of Electrodiagnostic Medicine (AAEM).

The nerve conduction studies were performed using standard techniques of supramaximal percutaneous stimulation with a constant current stimulator and surface electrode recording on both extremities of each subject. Sensory responses were obtained by antidromic stimulation at the wrist and recording from the index finger (for the median nerve) and little finger (for the ulnar nerve) using ring electrodes. The sensory responses of the radial nerve were obtained by antidromic stimulation at the middle of the forearm adjacent to the cephalic vein and recording with a disk electrode that was placed between the 1st and 2nd fingers.
The mean nerve conduction parameters of this population were compared to the existing literature values. Simple biometric measurements were also performed. The groups were matched according to the weight, height, limb length and perimeters of arm, and forearm (Table 1). We measured the length of the dominant upper limb as the distance between the acromial angle and the tip of the 3rd digit of the hand when the shoulder was flexed to $90^{\circ}$ with the elbow extended. The perimeters of the dominant arm and forearm were measured using a tape measure. The perimeter of the forearm was measured $10 \mathrm{~cm}$ proximal to the styloid process of the ulna, and the perimeter of the arm was measured $10 \mathrm{~cm}$ proximal to the medial epicondyle of the humerus.

\section{Statistical analyses}

The results are presented as $\mathrm{M} \pm \mathrm{SD}$. Differences between the groups were calculated using a non-parametric test for the independent samples (Mann-Whitney U-test). The SPSS package (Statistical Programs for Social Sciences, Chicago, Illinois, USA) for personal computer was used for statistical analyses. A p-value of less than 0.05 was considered significant.

This study was conducted according to the guidelines of the Declaration of Helsinki and was approved by the ethics committee of our faculty.

\section{RESULTS}

There were no significant differences in the length of the upper extremity and the perimeters of the dominant arm and forearm between the computer users and controls (Table 1).

Figure 1 shows the prevalence of musculoskeletal symptoms in the group of computer users. The 5 anatomical areas with the highest prevalence of musculoskeletal symptoms among the computer users were: neck (63\%), 


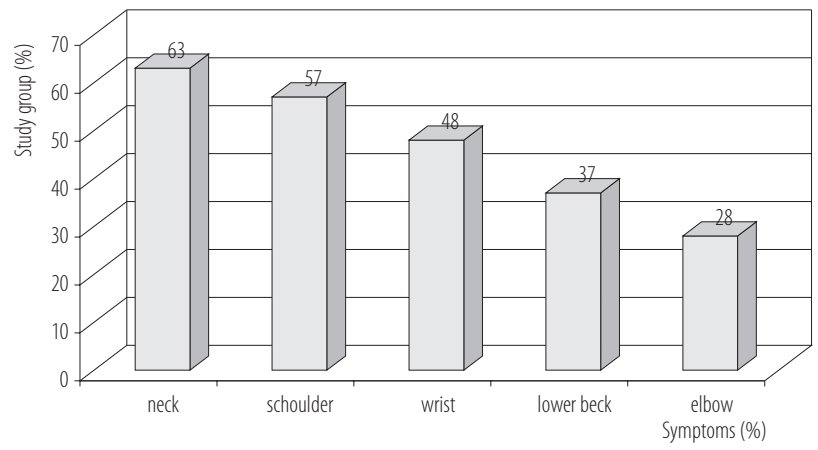

Fig. 1. Prevalence of musculoskeletal symptoms in the group of computer users

shoulder (57\%), wrist (48\%), lower back (37\%) and elbow $(28 \%)$.

Sensory conduction velocities of the median and ulnar nerves at the dominant extremity were significantly delayed in the computer users $(53.76 \pm 4.98 \mathrm{~m} / \mathrm{s}$ and $52.66 \pm 6.53 \mathrm{~m} / \mathrm{s}$, respectively) compared to the controls $(64.96 \pm 4.12 \mathrm{~m} / \mathrm{s}$ and $65.22 \pm 5.42 \mathrm{~m} / \mathrm{s}$, respectively). However, there was no statistical difference in conduction velocity of the radial sensory nerve between the control group and computer users ( $\mathrm{p}=0.375)$ (Table 2).

Sensory conduction velocities of the median and ulnar nerves at the non-dominant extremity were significantly delayed in the computer users $(57.30 \pm 4.81 \mathrm{~m} / \mathrm{s}$ and $49.47 \pm 5.54 \mathrm{~m} / \mathrm{s}$, respectively) compared to the controls $(63.01 \pm 7.27 \mathrm{~m} / \mathrm{s}$ and $62.53 \pm 7.41 \mathrm{~m} / \mathrm{s}$, respectively). However, there was no statistical difference in conduction velocity of the radial sensory nerve between the control group and computer users $(\mathrm{p}=0.396)$ (Table 3$)$.

We also compared the dominant and non-dominant extremities of the computer users with respect to their sensory nerve conduction velocities. Sensory conduction velocity of

Table 2. Nerve conduction velocities of dominant extremities among the computer users and the controls

\begin{tabular}{|c|c|c|c|}
\hline \multirow[t]{2}{*}{ Nerve } & \multicolumn{2}{|c|}{$\begin{array}{l}\text { Nerve conduction velocities } \\
(\mathrm{M} \pm \mathrm{SD}) \\
(\mathrm{m} / \mathrm{s})\end{array}$} & \multirow[t]{2}{*}{$\mathrm{p}$} \\
\hline & $\begin{array}{l}\text { computer users } \\
\quad(\mathrm{N}=21)\end{array}$ & $\begin{array}{l}\text { controls } \\
(\mathrm{N}=21)\end{array}$ & \\
\hline Median nerve & $53.76 \pm 4.98$ & $64.96 \pm 4.12$ & 0.000 \\
\hline Ulnar nerve & $52.66 \pm 6.53$ & $65.22 \pm 5.42$ & 0.000 \\
\hline Radial nerve & $84.24 \pm 16.20$ & $90.15 \pm 21.06$ & 0.375 \\
\hline
\end{tabular}

Abbreviations as in Table 1.

Table 3. Nerve conduction velocities of non-dominant extremities among the computer users and the controls

\begin{tabular}{|c|c|c|c|}
\hline \multirow[t]{2}{*}{ Nerve } & \multicolumn{2}{|c|}{$\begin{array}{l}\text { Nerve conduction velocities } \\
\qquad \begin{array}{c}(\mathrm{M} \pm \mathrm{SD}) \\
(\mathrm{m} / \mathrm{s})\end{array}\end{array}$} & \multirow{2}{*}{$\mathrm{p}$} \\
\hline & $\begin{array}{l}\text { computer users } \\
\quad(\mathrm{N}=21)\end{array}$ & $\begin{array}{l}\text { controls } \\
(\mathrm{N}=21)\end{array}$ & \\
\hline Median nerve & $57.30 \pm 4.81$ & $63.01 \pm 7.27$ & 0.006 \\
\hline Ulnar nerve & $49.47 \pm 5.54$ & $62.53 \pm 7.41$ & 0.000 \\
\hline Radial nerve & $78.07 \pm 13.66$ & $72.76 \pm 19.50$ & 0.396 \\
\hline
\end{tabular}

Abbreviations as in Table 1. 
Table 4. Nerve conduction velocities of dominant and non-dominant extremities of the computer users

\begin{tabular}{|c|c|c|c|}
\hline \multirow[t]{2}{*}{ Nerve } & \multicolumn{2}{|c|}{$\begin{array}{l}\text { Nerve conduction velocities } \\
(\mathrm{M} \pm \mathrm{SD}) \\
(\mathrm{m} / \mathrm{s})\end{array}$} & \multirow[t]{2}{*}{$\mathrm{p}$} \\
\hline & $\begin{array}{l}\text { dominant } \\
(\mathrm{N}=21)\end{array}$ & $\begin{array}{c}\text { nondominant } \\
(\mathrm{N}=21)\end{array}$ & \\
\hline Median nerve & $53.76 \pm 4.98$ & $57.30 \pm 4.81$ & 0.028 \\
\hline Ulnar nerve & $52.66 \pm 6.53$ & $49.47 \pm 5.54$ & 0.061 \\
\hline Radial nerve & $84.24 \pm 16.20$ & $78.07 \pm 13.66$ & 0.234 \\
\hline
\end{tabular}

Abbreviations as in Table 1.

the median nerve was significantly delayed in the dominant extremity of the computer users $(53.76 \pm 4.98 \mathrm{~m} / \mathrm{s})$ compared to their non-dominant extremity $(57.30 \pm 4.81 \mathrm{~m} / \mathrm{s}$, $p=0.028)$. There were no statistically significant differences in conduction velocities of the ulnar and radial nerves between the dominant and non-dominant extremities ( $p=0.061$ and $p=0.234$, respectively) (Table 4).

Although the computer users had conduction values that were significantly slower than those in the controls, their values were still within normal limits for the general population.

\section{DISCUSSION}

Computer use is often associated with the increased prevalence of hand and wrist disorders [2,7,8]. Non-neutral wrist postures have been associated with arm/hand symptoms among computer users [9]. Furthermore, the forces applied to the computer mouse and keyboard may constitute a risk factor for musculoskeletal symptoms [10]. The symptoms may be associated with specific clinical entities such as peripheral nerve entrapment.

The present study observed reduced mean SNCV in the median and ulnar nerves in the computer users compared with the controls. These slower SNCV findings in the neurologically asymptomatic computer users who spend much of their time using keyboard and mouse may correspond to preclinical lesions. We proposed that abnormal wrist mechanics such as prolonged extension of the wrist makes computer users vulnerable to ulnar and median nerve disorders.

Certain postures or positions can place increased pressure either directly or by increasing tension on the nerves at different entrapment points [5]. Wrist positions and forces employed by computer users have been evaluated in several studies. Sommerich et al. [11] have quantified the biomechanics of typing for 25 experienced computer users in 3 different occupational groups. The average tendon travel, normalized to $1 \mathrm{~h}$ of continuous typing, ranged from 30 to $59 \mathrm{~m} / \mathrm{h}$ for the 3 groups. Researchers have postulated that friction develops as a result of repetitive sliding of tendons within their sheaths during the performance of highly repetitive activities such as typing. This friction may contribute to disorders of tendons, their sheaths or adjacent nerves [12].

Determining whether there is a link between entrapment neuropathy and computer use is important due to the morbidity associated with entrapment neuropathies and the ever increasing use of computers in the workplace and at home [13]. Several studies have examined the relationship between computer usage and development of nerve disorder, and some of them showed that the long term computer users are at an increased risk for entrapment neuropathies in the upper extremity. 
Greening et al. [14] have examined flare responses, sympathetic vasoconstrictor reflexes and vibration threshold over areas of the hand innervated by the median, ulnar and radial nerves in the patients with repetitive strain injury and asymptomatic office workers who intensively used display screen equipment. While patients demonstrated clear indications of changed peripheral nerve function involving small and large sensory and autonomic fibres, office workers, who intensively used display screen equipment, showed early signs of changed sensory nerve function, but no change in autonomic responses.

Association between computer use and median nerve neuropathies has been investigated before. Jepsen [15] has studied a series of computer operators with upper limb complaints in the dominant upper limb. The author has identified sensory abnormalities in 19 out of 21 patients. The median nerve territory was most frequently involved. Greening and Lynn [16] have reported a significantly raised vibration threshold within the territory of the median nerve in a group of asymptomatic office workers using computer keyboard equipment, and have concluded that the results indicated a change in the function of large sensory fibres. Hashem et al. [17] have assessed the effect of the long-term use of computer mouse devices on the median nerve in healthy frequent computer users. They have reported physiological evidence suggestive of right median nerve entrapment neuropathy at the wrist. Our findings are in agreement with those studies which provide evidence regarding the close association between computer use and a reduced median nerve conduction velocity.

Median nerve enters the hand above the bones of the wrist by passing beneath the transverse carpal ligament. Compression of the median nerve at the wrist, or carpal tunnel syndrome (CTS), is the most common compressive neuropathy [18]. In recent years, with the expanding use of computers, it has been a matter of concern if computer use could be a risk factor for the development of CTS. However, contrasting results have been reported in the literature regarding association between computer use and CTS. A study by Murata et al. [19] has found a reduced sensory nerve conduction velocity in the median nerve across the carpal tunnel among neurologically symptomatic computer operators compared with healthy controls, indicating that a subclinical CTS was associated with computer use. However, other authors have reported that computer use had no influence on CTS occurrence [20,21].

The jobs with long periods of intensive mouse use may be at an increased risk of median neuropathy due to the increased carpal tunnel pressure [22]. Both ulnar deviation and extension of the wrist, increase carpal tunnel pressure [23,24].

Keir et al. [22] have suggested that 2 factors may account for the elevated carpal tunnel pressure during computer mouse use: wrist extension and the fingertip force applied to depress the button and to grip the sides of the mouse. With wrist extension angles greater than $15^{\circ}$, pressure in the carpal tunnel could result in more pressure against the median nerve, and this could contribute to the development or perpetuation of carpal tunnel syndrome [25]. Werner et al. [24] have noted that wrist extension stretches flexor tendons and median nerve, exerting pressure on their dorsal face. Low extraneural compression of the median nerve in the carpal tunnel is sufficient to produce edema within the nerve, and to impair endoneurial microcirculation. This compression has been demonstrated to be strongly influenced by repetitive fingertip loading, hand, wrist and forearm postures which may be seen during keyboard activity [26,27].

We found reduced SNCV in the median nerve among the computer users compared with the controls, indicating a subclinical CTS. However, the role of subclinical CTS is obscure and does not predict subsequent development of CTS. We found that the sensory conduction velocity of the median nerve was significantly delayed in the dominant extremity of the computer users compared to their non-dominant extremity. Generally, the demands 
placed on the upper extremities in computer users during typing occur bilaterally. At the same time, definitions of keyboard kinematics have documented that there were few significant differences between the right and left hand [28]. Simoneau et al. [29], have recorded $62^{\circ}$ and $66^{\circ}$ of mean pronation for the left and right forearms, respectively, in 90 professional touch typists during typing. One possible explanation of our finding is the long term computer mouse use by the dominant hand. This may indicate the increased neural deficits related to the increased use of the dominant side. Although one might have expected a delayed SCNC of the ulnar nerve in the dominant extremity of the computer users compared to their nondominant extremity, this is not supported by our data. We have no certain explanation for this finding.

Ulnar neuropathy can occur at the wrist just proximal to, within, or distal to Guyon's canal [30]. Ulnar nerve compression at Guyon's canal may be associated with an occupational disease in which the nerve is exposed to repetitive blunt trauma or high frequency vibration [31]. Guyon's canal syndrome, due to occupational overuse, has been attributed to prolonged flexion or extension of the wrist and repeated pressure on the hypothenar eminence [32]. It has been reported that approximately $10 \%$ of computer users who have work-related symptoms were found to have positive Tinel's sign over the Guyon's canal [33].

It has been speculated that pathologic processes causing CTS might be also expected to affect ulnar nerve at the wrist level $[34,35]$. Since a close contiguity exists between carpal tunnel and Guyon canal at the wrist level, there may be an association between CTS and ulnar nerve compression at the wrist.

The increased pressure in the carpal canal may exert mechanical traction on the transverse carpal ligament, which, together with the roof of the carpal tunnel, forms the medial wall and floor of Guyon's canal. Because carpal tunnel pressure alters median nerve function in a dose dependent manner, a similar effect may also affect ulnar axons [36].
Jensen et al. [4] have found an elevated vibration threshold in hand areas innervated by the median and ulnar nerves among computer users with pain in the upper limbs compared with a control group of computer users without such symptoms and a control group of subjects who do not use a computer. They have concluded that the findings indicated entrapment of the median and ulnar nerves. Another study has found a threshold effect for entrapment neuropathies ulnar and median nerves at the wrist, confirmed by nerve conduction, with an increased risk when the computer was used for more than $28 \mathrm{~h}$ per week [13].

Our results are in agreement with these studies on computer users showing a significant decrease in SNCV in both median and ulnar nerves. Ulnar nerve may be entrapped at Guyon's canal when the wrist is held in sustained extension and ulnar deviation. Given the similar anatomic position of the ulnar nerve and the median nerve at the wrist, the risk factors involved in computer use may be similar. In summary, awkward postures of the hand and wrist during typing and mouse use constitute a mechanism responsible for the observed differences in SNCV for the ulnar nerve seen in this investigation. Continual wrist extension may have resulted in the increased pressure on the ulnar nerve at the wrist and eventually caused subclinical focal neuropathy of the ulnar nerve.

In the radial nerve, we observed no significant differences in conduction velocity between the control group and computer users and there are no studies in the literature suggesting electrodiagnostic abnormalities of radial nerve in computer users. Although compression of the radial sensory nerve occurs between the tendons of the brachioradialis and the extensor carpi radialis longus muscles with forearm pronation [37], it appears that in the current study contraction of these muscles during typing didn't create compression force on the radial nerve. In fact, this result was expected, because the radial nerve is not in a vulnerable position as it lies through the wrist. In the wrist region, 
radial nerve function might not be clear compared with median and ulnar nerves.

\section{CONCLUSIONS}

Our study shows that computer users have a tendency to experience median and ulnar sensory nerve damage despite being neurologically asymptomatic. Sustained wrist extension and ulnar deviation may result in stretching of these nerves across the wrist during computer mouse use and typing. These results may represent presymptomatic or asymptomatic neuropathy similar to the type of subclinical entrapment neuropathy. In our opinion, clinicians interpreting CTS in the computer users should ask routinely about the symptoms of ulnar neuropathy at the wrist.

\section{REFERENCES}

1. Pilegaard M, Jensen BR. An 18-month follow-up study on vibrotactile sense, muscle strength and symptoms in computer users with and without symptoms. Int Arch Occup Environ Health. 2005;78(6):486-92, http://dx.doi.org/10.1007/s00420005-0626-6.

2. Gerr F, Marcus M, Ensor C, Kleinbaum D, Cohen S, Edwards A, et al. A prospective study of computer users: I. Study design and incidence of musculoskeletal symptoms and disorders. Am J Ind Med. 2002;41(4):221-35, http://dx.doi. org/10.1002/ajim.10066.

3. Tornqvist EW, Hagberg M, Hagman M, Risberg EH, Toomingas A. The influence of working conditions and individual factors on the incidence of neck and upper limb symptoms among professional computer users. Int Arch Occup Environ Health. 2009;82(6):689-702, http://dx.doi.org/10.1007/s00420009-0396-7.

4. Jensen BR, Pilegaard M, Momsen A. Vibrotactile sense and mechanical functional state of the arm and hand among computer users compared with a control group. Int Arch
Occup Environ Health. 2002;75(5):332-40, http://dx.doi. org/10.1007/s00420-001-0301-5.

5. Novak CB, Mackinnon SE. Multilevel nerve compression and muscle imbalance in work-related neuromuscular disorders. Am J Ind Med. 2002;41(5):343-52, http://dx.doi. org/10.1002/ajim.10063.

6. Gelberman RH, Szabo RM, Hargens AR. Pressure effect on human peripheral nerve function. In: Hargens AR, editors. Tissue nutrition and viability. New York, Berlin, Heidelberg, Tokyo: Springer; 1986. p. 161-84, http://dx.doi. org/10.1007/978-1-4684-0629-0_8.

7. Burgess RA, Pavlosky WF, Thompson RT. MRI-identified abnormalities and wrist range of motion in asymptomatic versus symptomatic computer users. BMC Musculoskelet Disord. 2010;11:273, http://dx.doi.org/10.1186/1471-247411-273.

8. Lassen CF, Mikkelsen S, Kryger AI, Brandt LP, Overgaard E, Thomsen JF, et al. Elbow and wrist/hand symptoms among 6,943 computer operators: A 1-year follow-up study (the NUDATA study). Am J Ind Med. 2004;46(5):521-33, http://dx.doi.org/10.1002/ajim.20081.

9. Wahlström J. Ergonomics, musculoskeletal disorders and computer work. Occup Med (Lond). 2005;55(3):168-76, http://dx.doi.org/10.1093/occmed/kqi083.

10. Feuerstein M, Armstrong T, Hickey P, Lincoln A. Computer keyboard force and upper extremity symptoms. J Occup Environ Med. 1997;39:1144-53, http://dx.doi. org/10.1097/00043764-199712000-00008.

11. Sommerich CM, Marras WS, Parnianpour M. A quantitative description of typing biomechanics. J Occup Rehab. 1996;6(1):33-55, http://dx.doi.org/10.1007/BF02110393.

12. Nelson JE, Treaster DE, Marras WS. Finger motion, wrist motion and tendon travel as a function of keyboard angles. Clin Biomech. 2000;15(7):489-98, http://dx.doi.org/10.1016/ S0268-0033(00)00011-5.

13. Conlon CF, Rempel DM. Upper extremity mononeuropathy among engineers. J Occup Environ Med. 2005;47(12):1276-84, http://dx.doi.org/10.1097/01.jom.0000181748.08188.8b. 
14. Greening J, Lynn B, Leary R. Sensory and autonomic function in the hands of patients with non-specific arm pain (NSAP) and asymptomatic office workers. Pain. 2003;104(1-2): 275-81, http://dx.doi.org/10.1016/S0304-3959(03)00010-1.

15. Jepsen JR. Upper limb neuropathy in computer operators? A clinical case study of 21 patients. BMC Musculoskelet Disord. 2004;5:26, http://dx.doi.org/10.1186/1471-2474-5-26.

16. Greening J, Lynn B. Vibration sense in the upper limb in patients with repetitive strain injury and a group of at-risk office workers. Int Arch Occup Environ Health. 1998;71(1):29-34, http://dx.doi.org/10.1007/s004200050246.

17. Al-Hashem FH, Khalid ME. The effect of long-term use of computer mouse devices on median nerve entrapment. Neurosciences. 2008;13(2):131-5.

18. Elman L, McCluskey L. Occupational and sport related traumatic neuropathy. 2004;10(2):82-96.

19. Murata K, Araki S, Okajima F, Saito Y. Subclinical impairment in the median nerve across the carpal tunnel among female VDT operators. Int Arch Occup Environ Health. 1996;68(2):75-9, http://dx.doi.org/10.1007/BF00381238.

20. Andersen JH, Thomsen JF, Overgaard E, Lassen CF, Brandt LP, Vilstrup I, et al. Computer use and carpal tunnel syndrome: A 1-year follow-up study. JAMA. 2003;289(22): 2963-9, http://dx.doi.org/10.1001/jama.289.22.2963.

21. Atroshi I, Gummesson C, Ornstein E, Johnsson R, Ranstam J. Carpal tunnel syndrome and keyboard use at work: A population-based study. Arthritis Rheum. 2007;56(11): 3620-5, http://dx.doi.org/10.1002/art.22956.

22. Keir PJ, Bach JM, Rempel D. Effects of computer mouse design and task on carpal tunnel pressure. Ergonomics. 1999;42(10):1350-60, http://dx.doi.org/10.1080/0014013991 84992.

23. Weiss ND, Gordon L, Bloom T, So Y, Rempel DM. Position of the wrist associated with the lowest carpal-tunnel pressure: Implications for splint design. J Bone Joint Surg Am. 1995;77(11):1695-9.

24. Werner R, Armstrong TJ, Bir C, Aylard MK. Intracarpal canal pressures: The role of finger, hand, wrist and forearm position. Clin Biomech. 1997;12(1):44-51, http://dx.doi.org/ 10.1016/S0268-0033(96)00044-7.

25. Simoneau GG, Marklin RW, Berman JE. Effect of computer keyboard slope on wrist position and forearm electromyography of typists without musculoskeletal disorders. Phys Ther. 2003;83(9):816-30.

26. Rempel DM, Diao E. Entrapment neuropathies: Pathophysiology and pathogenesis. J Electromyogr Kinesiol. 2004;14(1): 71-5, http://dx.doi.org/10.1016/j.jelekin.2003.09.009.

27. Johnston V, Jimmieson NL, Jull G, Souvlis T. Quantitative sensory measures distinguish office workers with varying levels of neck pain and disability. Pain. 2008;137(2):257-65.

28. Baker NA, Cham R, Cidboy EH, Cook J, Redfern MS. Kinematics of the fingers and hands during computer keyboard use. Clin Biomech. 2007;22(1):34-43, http://dx.doi. org/10.1016/j.clinbiomech.2006.08.008.

29. Simoneau GG, Marklin RW, Monroe JF. Wrist and forearm postures of users of conventional computer keyboards. Hum Factors. 1999;41(3):413-24, http://dx.doi.org/10.1518/ 001872099779610978.

30. Shea JD, McClain EJ. Ulnar-nerve compression syndromes at and below the wrist. J Bone Surg Am. 1969; 51(6):1095-103.

31. Palmer KT. Carpal tunnel syndrome: The role of occupational factors. Best Pract Res Clin Rheumatol. 2011;25(1): 15-29, http://dx.doi.org/10.1016/j.berh.2011.01.014.

32. Yassi A. Repetitive strain injuries. Lancet. 1997; 349(9056):943-7, http://dx.doi.org/10.1016/S0140-6736(96) 07221-2.

33. Pascarelli EF, Hsu YP. Understanding work-related upper extremity disorders: Clinical findings in 485 computer users, musicians, and others. J Occup Rehabil. 2001;11(1):1-21, http://dx.doi.org/10.1023/A:1016647923501.

34. Cassvan A, Rosenberg A, Rivera LF. Ulnar nerve involvement in carpal tunnel syndrome. Arch Phys Med Rehabil. 1986;67(5):290-2.

35. Gozke E, Dortcan N, Kocer A, Cetinkaya M, Akyuz G, Us $\mathrm{O}$. Ulnar nerve entrapment at wrist associated with 
carpal tunnel syndrome. Neurophysiol Clin. 2003;33(5): 219-22, http://dx.doi.org/10.1016/j.neucli.2003.08.002.

36. Ginanneschi F, Milani P, Mondelli M, Dominici F, Biasella A, Rossi A. Ulnar sensory nerve impairment at the wrist in carpal tunnel syndrome. Muscle Nerve. 2008;37(2):183-9, http://dx.doi.org/10.1002/mus.20905.
37. Dellon AL, Mackinnon SE. Radial sensory nerve entrapment in the forearm. J Hand Surg. 1986;11A:199-205, http://dx.doi.org/10.1016/S0363-5023(86)80051-X.

This work is available in Open Access model and licensed under a Creative Commons Attribution-NonCommercial 3.0 Poland License - http://creativecommons.org/ licenses/by-nc/3.0/pl/deed.en. 